\title{
Whiplash and Concussion: Similar Acute Changes in Middle-Latency SEPs
}

\author{
Dominik Zumsteg, Richard Wennberg, Eva Gütling, Klaus Hess
}

\begin{abstract}
Objective: Middle-latency somatosensory evoked potentials (SEPs) following median nerve stimulation can provide a sensitive measure of cortical function. We sought to determine whether the mechanical forces of whiplash injury or concussion alter normal processing of middle-latency SEPs. Methods: In a cross-sectional pilot study 20 subjects with whiplash were investigated (50\% between 0.5-2 months and 50\% between 6-41 months post injury) and compared to 83 healthy subjects using a standard middle-latency SEP procedure. In a subsequent prospective study subjects with either acute whiplash $(\mathrm{n}=13)$ or Grade 3 concussion ( $\mathrm{n}=16)$ were investigated within 48 hours and again three months post injury. Results: In the pilot study the middle-latency SEP component N60 was significantly increased in the ten subjects investigated within two months after whiplash. In contrast, the ten subjects examined more than six months after injury showed normal latencies. In the prospective study N60 latencies were increased after whiplash and concussion when tested within 48 hours of injury. At three months, latencies were improved though still significantly different from controls post whiplash and concussion. Conclusions: Both whiplash injury and concussion alter processing of the middle-latency SEP component N60 in the acute post traumatic period. The acute changes appear to normalize between three-six months post injury. The SEP similarities suggest that the overlapping clinical symptomatology post whiplash and concussion may reflect a similar underlying mechanism of rotational mild traumatic brain injury.
\end{abstract}

RÉSUMÉ: Coup de fouet cervical et commotion cérébrale : similitude des changements aigus des potentiels évoqués somesthésiques de latence moyenne. Objectif : Les potentiels évoqués somesthésiques (PÉSs) de latence moyenne obtenus par stimulation du nerf médian constituent une mesure sensible de la fonction corticale. Le but de cette étude était de déterminer si les forces mécaniques impliquées dans le coup de fouet cervical et dans la commotion cérébrale altèrent le traitement normal des PÉSs de latence moyenne. Méthodes : Il s'agit d'une étude pilote transversale au cours de laquelle nous avons évalué 20 sujets qui avaient subi un coup de fouet cervical. La moitié des sujets ont été évalués entre 0,5 à 2 mois après l'incident et l'autre moitié de 6 à 41 mois après. Nous les avons comparés à 83 sujets témoins en santé au moyen de la technique standard d'évaluation des PÉSs de latence moyenne. Au cours d'une étude prospective subséquente, nous avons évalué des sujets présentant soit un coup de fouet cervical aigu ( $\mathrm{n}=$ 13) ou une commotion cérébrale de grade $3(\mathrm{n}=16)$ dans les 48 heures de l'incident et 3 mois après. Résultats : Dans l'étude pilote, la composante de latence moyenne N60 était significativement augmentée chez les dix sujets évalués dans les deux premiers mois après l'incident. Par contre, les dix sujets examinés plus de six mois après l'incident avaient des latences normales. Dans l'étude prospective, les latences N60 étaient augmentées après le coup de fouet cervical et la commotion cérébrale lors de l'évaluation faite dans les 48 heures de l'incident. Après trois mois, les latences étaient améliorées chez les sujets ayant subi un coup de fouet cervical ou une commotion cérébrale, même si elles demeuraient significativement différentes de celles des témoins. Conclusions : Le coup de fouet cervical et la commotion cérébrale modifient le traitement de la composante N60 des PÉSs de latence moyenne au cours de la période post-traumatique aiguë. Les changements aigus semblent se normaliser entre trois et six mois après la blessure. La similitude des PÉSs suggère que le chevauchement de la symptomatologie clinique après le coup de fouet cervical et après la commotion cérébrale puisse refléter un mécanisme sous-jacent similaire soit une légère lésion cérébrale traumatique rotatoire.

Can. J. Neurol. Sci. 2006; 33: 379-386

Whiplash injuries resulting from rear-end collisions in motor vehicle accidents generally show good recovery, but persistent symptoms have been frequently reported in a subgroup of patients. $^{1-4}$ Concussion injuries are also usually followed by good recovery, however, there does exist a subgroup of patients with persistent post concussion symptoms. ${ }^{5-8}$ Although the two conditions are rarely considered together, it is noteworthy that the constellation of post whiplash and post concussion symptoms are essentially identical (headache, memory impairment, poor concentration, sleep disturbance, anxiety, depression, vertigo, fatigue, irritability), apart from the more prominent component of neck pain with whiplash and the

From the Krembil Neuroscience Centre (DZ, RW), Toronto Western Hospital, University of Toronto, Toronto, ON, Canada; Department of Neurology (EG, KH), University Hospital, Zurich, Switzerland. ReCEIVEd March 20, 2006. AcCEPTED In FinAl FORM June 27, 2006. Reprint requests to: Dominik Zumsteg, Krembil Neuroscience Centre, University of Toronto, Toronto Western Hospital, 5W-425, 399 Bathurst Street, Toronto, Ontario, M5T 2S8, Canada. 
transient loss of consciousness that defines the most severe, or Grade $3,{ }^{8}$ concussions. It is thus possible that the acute and chronic clinical symptomatology of whiplash and concussion might reflect a similar mechanism of mild traumatic brain injury, with differences in the degree of presentation representing differences in the severity of applied mechanical force along a continuum of mild traumatic brain injury.

The pathophysiological changes underlying the cerebral symptoms of whiplash and concussion are unresolved. ${ }^{9,10}$ Standard laboratory investigations including high resolution magnetic resonance imaging (MRI) of the brain are typically unrevealing, even in patients with chronic, persistent symptoms. A laboratory test capable of identifying an objective neurophysiological marker for mild traumatic brain injury would be useful not only for clinical diagnostic and prognostic purposes, but also for understanding the underlying pathophysiological mechanisms and, for example, the differences or similarities between whiplash and concussion injuries. Preliminary studies have been reported showing some promising results in this regard using cognitive event-related potential (P300) testing in athletes with post concussion symptoms. ${ }^{11,12}$

Knowing that components of the middle-latency somatosensory evoked potentials (SEPs) are generated in the primary somatosensory cortex $x^{13-15}$ and considering that severe rotational acceleration injury has been consistently shown to cause damage or dysfunction at the surface of the brain in parasagittal parietal zones in experimental studies of whiplash and concussion, ${ }^{10,16-20}$ we thought it may be promising to focus on middle-latency SEPs in the search for a neurophysiological marker for mild traumatic brain injury. There is much evidence indicating middle-latency SEPs to be a sensitive measure of cortical function. Various studies have reported their reliability for objective assessment and quantification of cerebral dysfunction and prognostic evaluation in patients with severe head injury, ${ }^{21-26}$ anoxic coma, ${ }^{27-29}$ liver failure, ${ }^{30-34}$ and other metabolic or infectious encephalopathies. ${ }^{35,36}$ Studies investigating the use of middle-latency SEPs in patients with whiplash injury or concussion have not been reported to our knowledge.

\section{SubJeCtS ANd Methods}

\section{Pilot study}

The inclusion criteria for this pilot study were based on a history of whiplash injury. Whiplash was defined strictly according to previous research criteria, i.e. sudden acceleration and hyperextension of the neck occurring in all cases as a result of rear-end motor vehicle collisions. ${ }^{18,37-40}$ A detailed history with special emphasis on self-reported symptoms and on any drug-intake was obtained from all subjects using a structured interview before SEP recording (patients were specifically encouraged to abstain from the ingestion of sedative or analgesic drugs until SEP recordings were carried out). Subjects with additional impact trauma, traumatic loss of consciousness, previous injuries or diseases of the central nervous system were not included. All subjects underwent complete neurological examination before SEP recording. Brain computed tomography or MRI was not performed. Informed consent and approval from the local ethics committee (University Hospital Zurich) were obtained.
The study population consisted of two distinct groups that differed with respect to the time intervals between whiplash injuries and SEP recordings. The first ("acute") group consisted of ten subjects (seven women) with a mean age of 35.7 years (range 18 to 62 years) and a time lag between whiplash injury and SEP recording of 25.4 days (range 14 to 63 days). Subjects in this group were consecutively recruited from the emergency unit of the University Hospital Zurich. The second ("chronic") group consisted of ten subjects (three women) with a mean age of 36.6 years (range 22 to 62 years) and a time lag between whiplash injury and SEP recording of 15.6 months (range 5.9 to 41.3 months). Subjects in this group were consecutively recruited from the University Hospital Zurich neurological outpatient clinic. Eighty-three healthy subjects (47 women) with a mean age of 42 years (range 13 to 80 years), as previously published, ${ }^{41}$ served as controls.

\section{Prospective study}

In a subsequent prospective study, consecutive patients with acute whiplash were identified upon presentation to the emergency unit of the University Hospital Zurich. In addition, consecutive patients presenting to the same emergency unit with a diagnosis of concussion with loss of consciousness (i.e. Grade 3 concussion) were recruited over the same time period. As with the cross-sectional pilot study, whiplash injury resulted from rear-end motor vehicle collisions in all cases and subjects with additional impact trauma or traumatic loss of consciousness were not included. Concussions were incurred via a variety of mechanisms in the patients recruited, including work-related head injuries, sports-related head injuries, and direct blows to the head received during interpersonal conflicts. As with the pilot study, a detailed history with special emphasis on self-reported symptoms, using a visual analog scale, and on any drug-intake was obtained from all subjects using a structured interview before SEP recording. Whiplash subjects with additional impact trauma, traumatic loss of consciousness, previous injuries or diseases of the central nervous system were not included. Concussion subjects with previous injuries or diseases of the central nervous system were not included. All subjects underwent complete neurological examination before SEP recording. Neuroimaging with MRI was performed in all patients. These MRI scans were normal except in one patient with a small left subdural hematoma and associated temporoparietal contusion resulting from a punch to the head. Informed consent and approval from the local ethics committee (University Hospital Zurich) were obtained.

Sixteen concussion patients with a mean age of 35.4 years (range 19 to 64 years) and 13 whiplash patients with a mean age of 37.6 years (range 22 to 62 years) were simultaneously recruited over the same time period. All of these subjects were tested with SEP recording within 48 hours of injury, and again at three months post injury.

\section{SEP recordings}

The SEP recordings were performed in a quiet, semidarkened room. Subjects were encouraged to relax and to keep their eyes closed. Square wave impulses of $0.2 \mathrm{~ms}$ duration were delivered at a rate of $2 \mathrm{~Hz}$ to the median nerve at the wrist. Stimulus intensity was slightly above motor threshold producing 
a moderate thumb twitch. Silver-disc recording electrodes were placed over Erb's point, over the second cervical vertebra (C2), over the contralateral parietal $(2 \mathrm{~cm}$ posterior and $7 \mathrm{~cm}$ lateral to the vertex) and frontal scalp (at electrode positions F3 or F4 according to the international 10-20 system). All electrodes were referenced to linked earlobes. Electrode impedance was kept below $5 \mathrm{k} \Omega$. Analysis time was $200 \mathrm{~ms}$ and filter bandpass was set at $1-1000 \mathrm{~Hz}(-3 \mathrm{~dB})$ for the scalp and at $50-2000 \mathrm{~Hz}(-3 \mathrm{~dB})$ for the Erb's point and $\mathrm{C} 2$ recordings. Each examination included two series of at least 512 trials on both sides. The peak latencies of the cervical component N13, the parietal components N20, P45, N60 and the frontal component N30 were evaluated. The interpeak latencies N13-N20 (known as central conduction time, CCT) and N13-N60 were calculated.

\section{Statistical analysis}

Statistical analysis was performed using the Statistical Package for Social Sciences (SPSS 9.0 for Windows). Latency

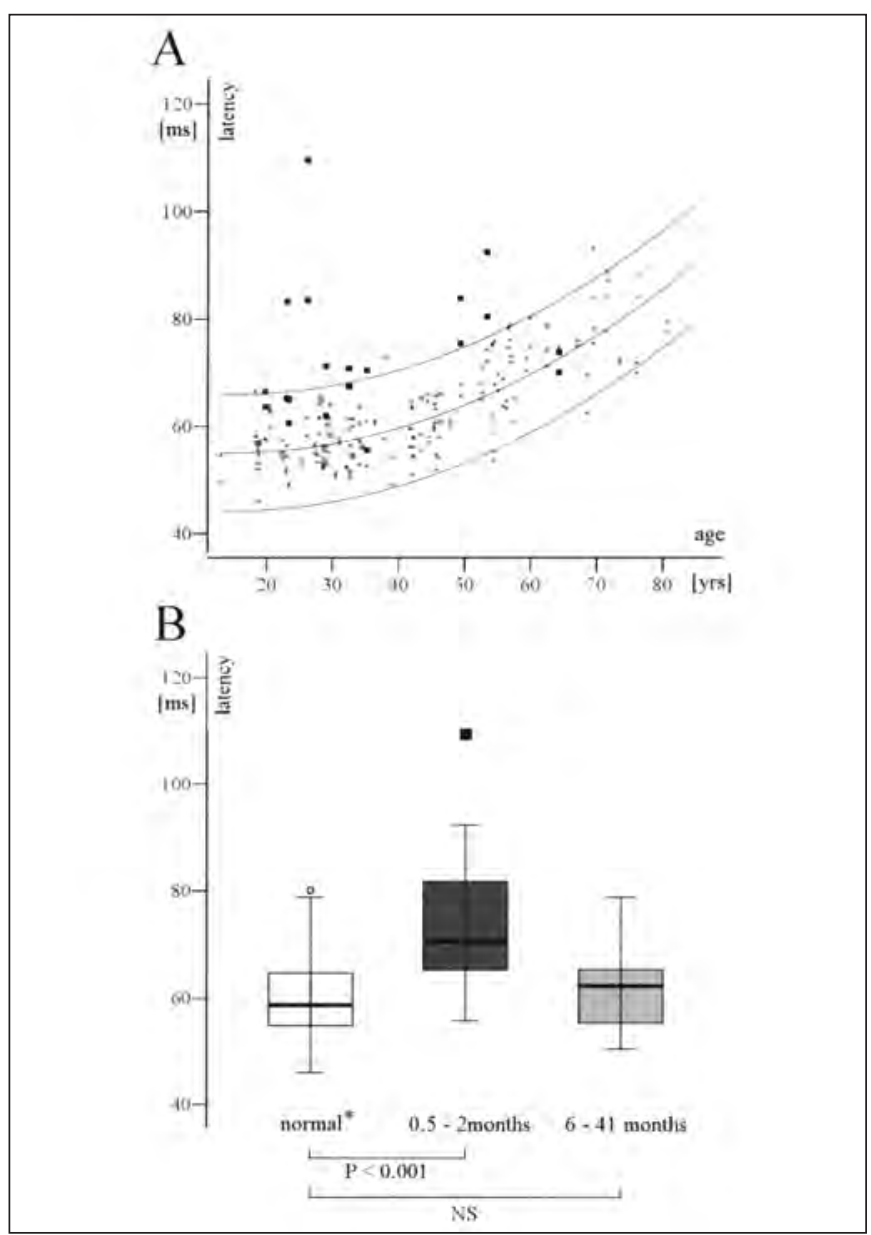

Figure 1: Whiplash injury, pilot study. A) SEP N60 latencies of the "acute" (black squares) and the "chronic" group (gray squares) patients in comparison to normative data (small circles). B) Corresponding boxplots of both groups in comparison to normative data. ${ }^{41}$ (*) Note that only the values of patients aged 19 to 65 years were included for statistical analysis. Boxes indicate 25\%, 50\% and $75 \%$ percentiles, whiskers $5 \%$ and $95 \%$ percentiles, and circles or squares outliers. values are expressed as median \pm standard deviation. Betweengroup and between-side differences were assessed using the Mann-Whitney U test. Pearson correlation was used for the assessment of correlation between SEP values and continuation of symptoms at three month clinical follow-up.

\section{Results}

\section{Pilot study}

The self-reported symptoms of the subjects with whiplash injury at the time of SEP recording included headache $(3 / 10$ "acute" and 5/10 "chronic"), neck pain (5/10 "acute" and 7/10 "chronic"), vertigo (1/10 "acute" and 4/10 "chronic"), forgetfulness and poor concentration (2/10 "acute" and 7/10 "chronic"), fatigue (1/10 "acute" and 3/10 "chronic") and depression (0/10 "acute" and 4/10 "chronic"). Neurological assessment of the central and peripheral nervous system was normal in all subjects.

Middle-latency SEPs were easily recorded in all subjects. All subjects were examined whilst no neuroactive drugs were being prescribed, although one subject of the "chronic" group had taken a benzodiazepine (oxazepam $15 \mathrm{mg}$ ) about 18 hours before SEP recording. Figure 1A depicts the latencies of N60 in both groups in comparison to normative data. The latencies of the N60 components and the interpeak N13-60 latencies were significantly increased in the "acute" group but not in the "chronic" group (Table and Figure 1). No differences were found for other SEP components (N13, N20, frontal N30) or the CCT interpeak latencies in either group (data not shown).

\section{Prospective study}

Middle-latency SEPs were easily recorded in all subjects except in the case of the concussion patient with the left temporoparietal contusion and subdural hemorrhage, in whom middle-latency SEPs were not obtainable upon stimulation of the right median nerve in the acute setting. However, upon retesting this patient at three months the middle-latency SEPs were obtainable to stimulation of the right median nerve. The SEP testing, both within 48 hours and at three months, was performed with subjects receiving no prescribed neuroactive drugs. Figures 2 and 3 depict the latencies of N60 in the prospective whiplash and concussion groups, comparing the testing performed within 48 hours of injury with the follow-up testing performed at three months, all in comparison to normative data. The latencies of the N60 components and the interpeak N13-60 latencies were significantly increased after whiplash and concussion when tested within 48 hours of injury. These increases were significantly more pronounced in patients post concussion in comparison to patients post whiplash $(\mathrm{p}<0.001)$. At three months, N60 latencies and the interpeak N13-60 latencies were improved in subjects though still significantly different from controls post whiplash and concussion (Table). Figure 4 shows a representative example of the N60 latencies recorded at 48 hours and at three months in a subject whose concussion resulted from a high speed bicycling accident. No differences were found for other SEP components (N13, N20, frontal N30) or the CCT interpeak latencies in either group (data not shown).

Figure 5 depicts the self-reported complaints of the whiplash and concussion subjects in the prospective study, both acutely 


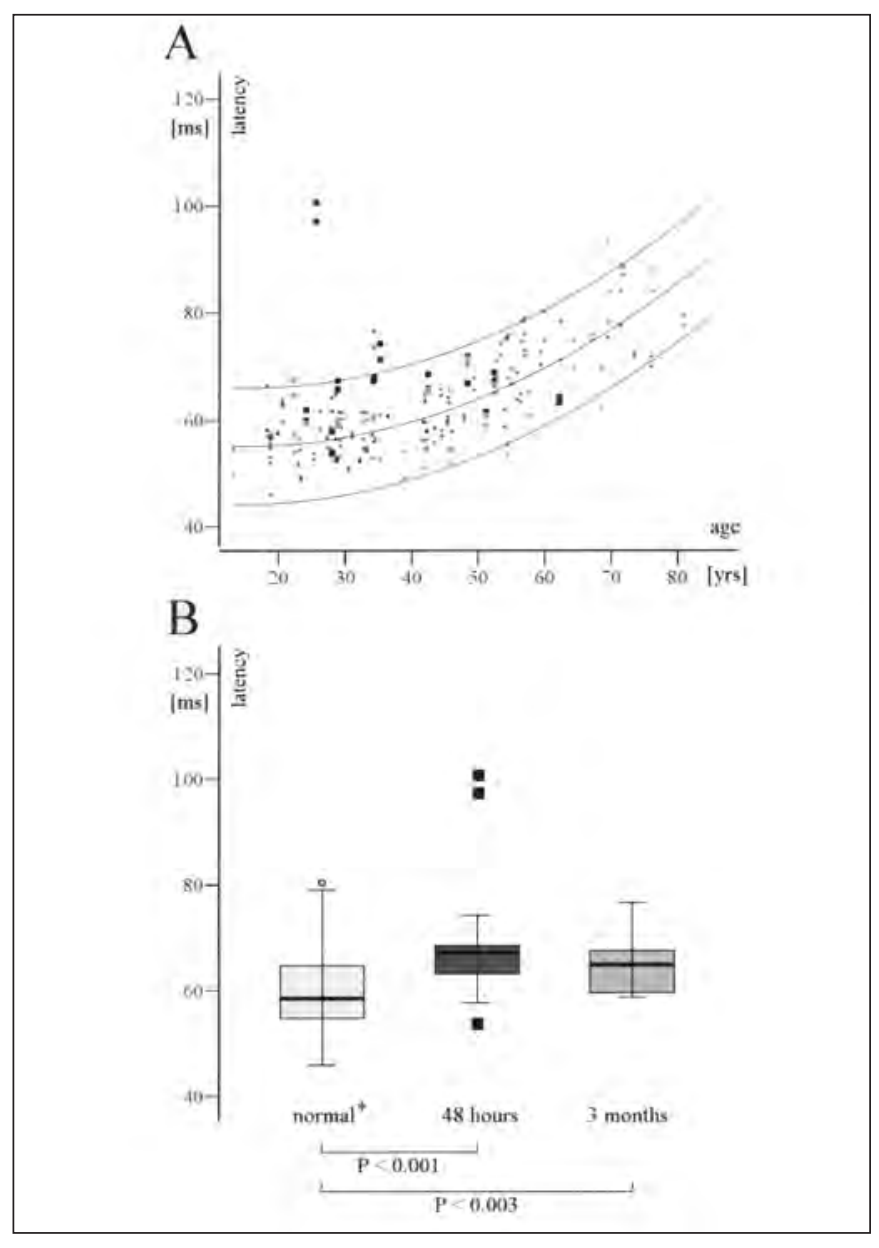

Figure 2: Whiplash injury, prospective study. A) SEP N60 latencies in the acute setting ( $<48$ hours, black squares) and at retesting 3 months (gray squares) after whiplash injury in comparison to normative data (small circles). B) Corresponding boxplots of both groups in comparison to normative data. (*) Only the values of patients aged 19 to 65 years were included for statistical analysis.

and at three month clinical follow-up. Despite the significant improvement in N60 latencies in both groups at three month follow-up, self-reported clinical symptomatology worsened over time in many domains in the whiplash group, whereas almost all complaints in the concussion group improved over time.

\section{Discussion}

In the pilot study we found a significant increase in the N60 latency in subjects in whom the SEP recordings were performed within three months after whiplash injury. On the other hand, the latency of the N60 component was shown to be within normal limits if the recordings were performed after a period greater than three months post injury. It must be acknowledged that the two groups in the cross-sectional pilot study cannot be compared directly since subjects in the "acute" and "chronic" groups were recruited from two distinct collectives. However, the suggestive findings from the pilot study were strengthened by the findings

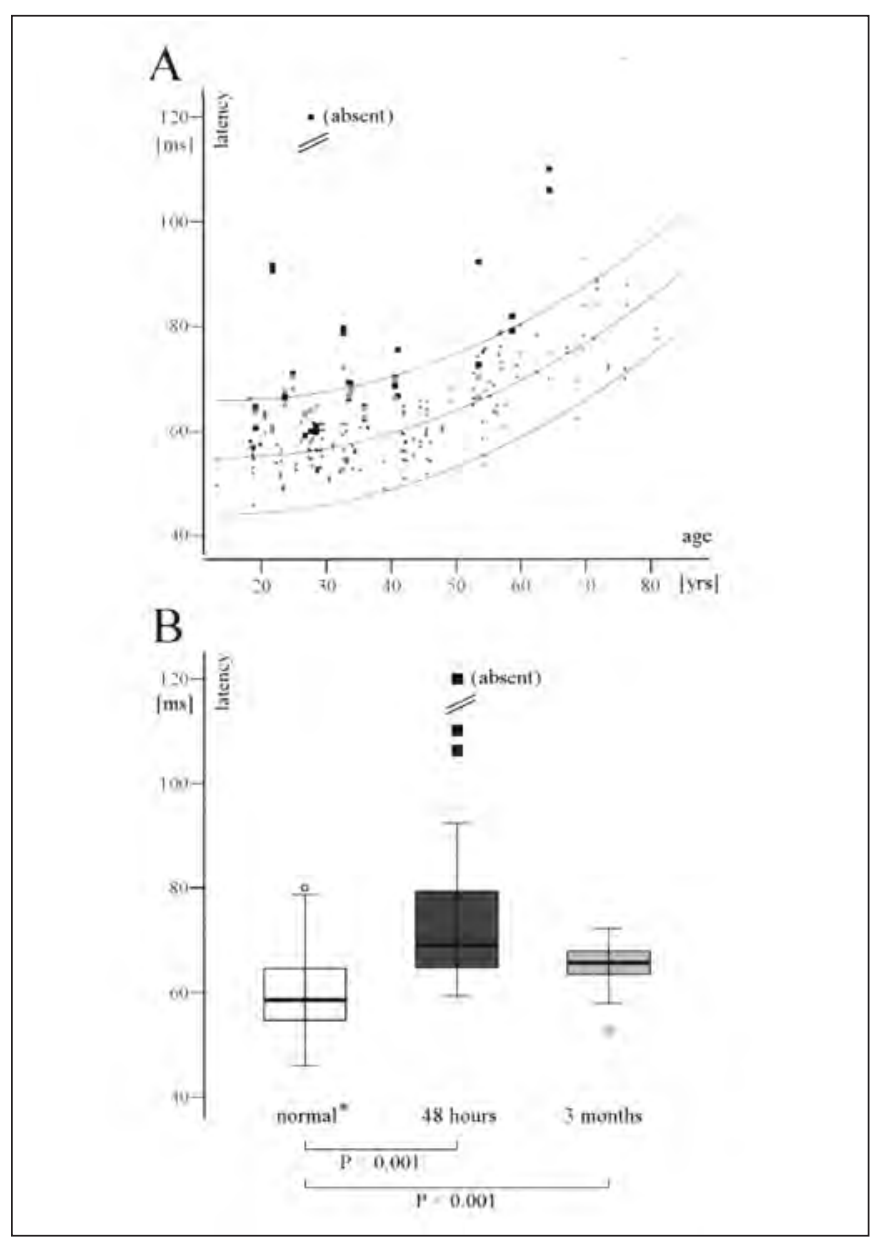

Figure 3: Concussion, prospective study. A) SEP N60 latencies in the acute setting ( $<48$ hours, black squares) and at retesting 3 months (gray squares) after concussion in comparison to normative data (small circles). B) Corresponding boxplots of both groups in comparison to normative data. (*) Only the values of patients aged 19 to 65 years were included for statistical analysis.

of the prospective study, which extended the results to show similar acute changes in N60 latency after whiplash and concussion. Thus, both whiplash injury and concussion may alter processing of the middle-latency SEP component N60 in the early post traumatic period. In the concussion patients, the increase in N60 latencies was significantly more pronounced than in the whiplash patients, and the normalization of N60 latencies was less complete at three months in the post concussion group compared to the post whiplash group. This could be interpreted to reflect the greater severity of injury in the concussion patients.

From the results of both studies, it would appear that the acute changes in N60 latency normalize between three to six months post injury. It is thus evident that the acute increase in N60 latency is related to reversible traumatic functional abnormalities in the brain of patients post whiplash or concussion injury. Middle-latency SEPs are considered to be a sensitive measure of 
Table: Latency N60 and interpeak latency N13-N60

\begin{tabular}{|c|c|c|c|c|c|c|}
\hline & \multicolumn{2}{|c|}{ Pilot study whiplash } & \multicolumn{2}{|c|}{ Prosp. study whiplash } & \multicolumn{2}{|c|}{ Prosp. study concussion } \\
\hline & "acute" & "chronic" & acute & follow-up & acute & follow-up \\
\hline Normal N60 [ms]* & $58.6 \pm 7.3$ & $58.6 \pm 7.3$ & $58.6 \pm 7.3$ & $58.6 \pm 7.3$ & $58.6 \pm 7.3$ & $58.6 \pm 7.3$ \\
\hline N60 $[\mathrm{ms}]^{*}$ & $70.6 \pm 12.5$ & $62.2 \pm 7.6$ & $67.3 \pm 10.1$ & $64.9 \pm 5.5$ & $69.2 \pm 15.3$ & $65.6 \pm 14.3$ \\
\hline Mann-Whitney U & 457 & 1268 & 875 & 753 & 768 & 946 \\
\hline $\mathbf{Z}$ & -4.98 & -0.95 & -4.37 & -2.95 & -5.97 & -3.64 \\
\hline $\mathbf{p}$ & $\mathrm{p}<0.001$ & NS & $\mathrm{p}<0.001$ & $\mathrm{p}<0.003$ & $\mathrm{p}<0.001$ & $\mathrm{p}<0.001$ \\
\hline Normal N13-60 [ms] * & $45.4 \pm 7.0$ & $45.4 \pm 7.0$ & $45.4 \pm 7.0$ & $45.4 \pm 7.0$ & $45.4 \pm 7.0$ & $45.4 \pm 7.0$ \\
\hline N13-60 $[\mathrm{ms}]^{*}$ & $57.2 \pm 12.5$ & $47.1 \pm 7.4$ & $52.9 \pm 9.9$ & $50.8 \pm 5.6$ & $55.2 \pm 15.1$ & $51.4 \pm 4.3$ \\
\hline Mann-Whitney U & 476 & 1325 & 893 & 789.5 & 722.5 & 932 \\
\hline $\mathbf{Z}$ & -4.88 & -0.67 & -4.30 & -2.76 & -6.11 & -3.67 \\
\hline $\mathbf{p}$ & $\mathrm{p}<0.001$ & NS & $\mathrm{p}<0.001$ & $\mathrm{p}<0.006$ & $\mathrm{p}<0.001$ & $\mathrm{p}<0.001$ \\
\hline
\end{tabular}

*Latency values are expressed as median \pm standard deviation.

cortical integrity. ${ }^{26,28,36}$ Pfutscheller et $\mathrm{al}^{26}$ reported a clear correlation between the latency delay of middle-latency SEPs and the severity of coma and concluded that middle-latency components might be useful in the prediction of outcome and suggested that middle-latency SEP components might be even more sensitive in patients with mild head injury.

Considering the neural generators of the N60 component and the mechanisms of both whiplash and rotational acceleration head injury, an increase of the N60 latency in patients post injury is not necessarily surprising. Middle-latency SEP components are thought to be related to complex interactions between the thalamo-cortical, cortico-cortical and ascending reticular activation systems. ${ }^{26,42}$ Investigations using cortical-surface and transcortical recordings during neurosurgery have suggested that the N60 component is composed of two spatially distinct potentials being generated in area 1 and area $3 \mathrm{~b}$ of the primary somatosensory cortex. ${ }^{14,15,43}$ Thus, mechanical forces sufficient to temporarily affect these neuronal structures (i.e. the superficial parietal cortex) in a direct or indirect way may be sufficient to produce the observed SEP changes. In this context, the results from experimental studies are informative. Various investigations in subhuman primates have demonstrated that severe rotational acceleration (without direct head impact) can produce consistent brain damage, as evidenced by marked hemorrhages or contusions at the surface of the brain including the parasagittal parietal zones. ${ }^{16-19}$ One interesting experimental study using a simple but convincing gelatin model to elucidate the consequences of rotational acceleration trauma to the brain revealed a clear predilection of the parasagittal parietal and superstitial orbitofrontotemporal regions to sustain injury. ${ }^{44}$ Besides these superficial lesions, many studies have demonstrated that closed head injury can result in diffuse axonal injury in the white matter of the brain. ${ }^{17,45,46}$ Diffuse axonal injury resulting in diffuse target deafferentation of cortical structures has been proposed as another possible mechanism to explain the effects of rotational head injury, and could possibly explain the observed increase of the N60 latency. However, evidence for diffuse axonal injury is lacking in mild traumatic

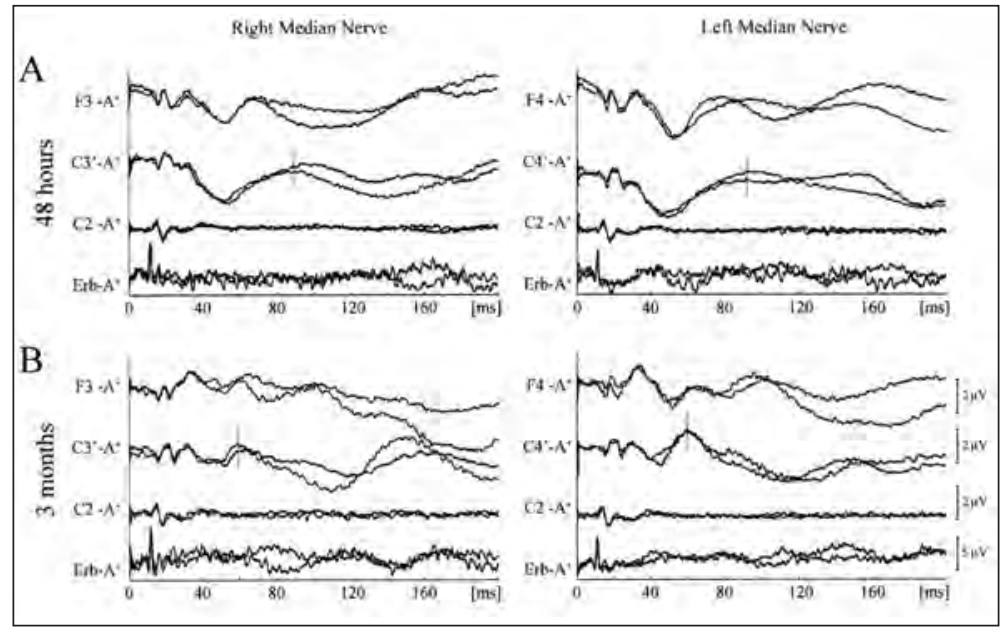

Figure 4: Representative SEP recordings performed at 48 hours and at 3 months in a subject with concussion. 


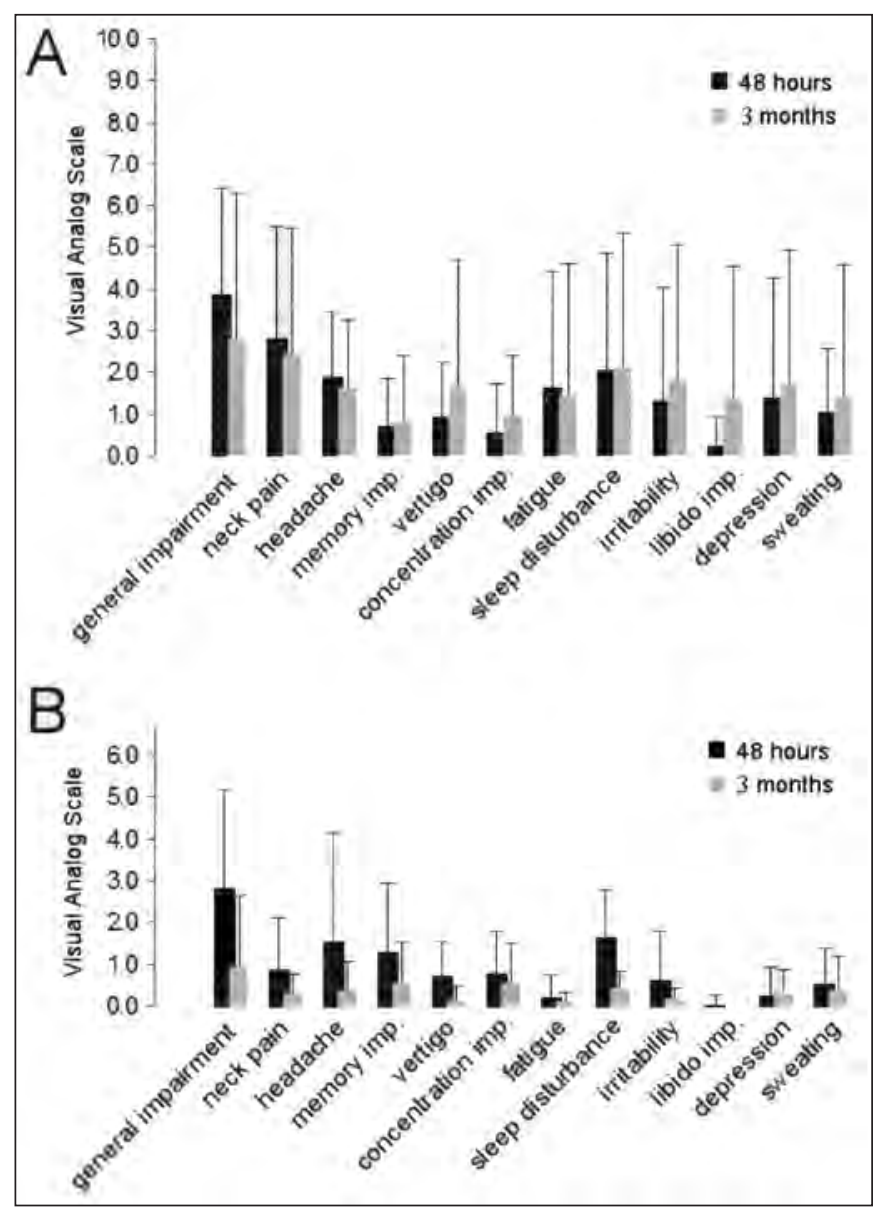

Figure 5: Self-reported complaints (VAS) of the whiplash (A) and concussion (B) subjects in the prospective study, both acutely and at 3 month clinical follow up. There was no significant correlation between SEP values and continuation of symptoms at 3 month clinical follow-up, for any of the self-reported complaints.

brain injury and experimental SEP findings in rat models of concussion (where early components are preserved and late components affected) are most suggestive of delayed intracortical processing, rather than cortical deafferentation. ${ }^{10,20}$ Perhaps most relevant to mild traumatic brain injury are the neurochemical changes (e.g. massive ionic fluxes across plasma membranes, increase in excitatory amino acids) that are well known to occur post trauma, ${ }^{10,47,48}$ and which could lead to a temporary diffuse brain damage affecting N60 generation in a direct or indirect way.

Several concerns commonly mentioned regarding the usefulness of middle-latency SEP components in a clinical setting need to be discussed in the context of our results. Firstly, we would like to emphasize that the common conviction that middle-latency SEP components show considerable interindividual variability even in healthy subjects is simply incorrect. We have previously shown that middle-latency SEP components can be easily recorded with small inter-trial and inter-individual variability over a wide range of ages in healthy subjects (as seen in Figures 1-3 of this study). ${ }^{41}$ The influence of drowsiness on middle-latency SEP components is another factor commonly mentioned. In fact, increases in latency and amplitude of SEP components in sleep have been shown in several studies, ${ }^{49,50}$ but these changes are usually only moderate up to sleep Stage 2. In our study, we tried to overcome the bias of drowsiness by encouraging our subjects to keep awake during recordings and by talking with them after each run. Furthermore, the appropriate analysis of our data (comparison of the two repetitions of each run; see, for example, Figure 4) did not show any significant differences (data not shown). Another factor that is well recognized as affecting middle-latency SEP components is the influence of neuroactive drugs. ${ }^{43,51}$ Since only one of our pilot study subjects had taken a low dose of a short-acting benzodiazepine about 18 hours before SEP recording, and especially as this subject was not part of the "acute" group, we suggest that the influence of neuroactive drugs does not call into question the validity of our results.

The similarity of the clinical symptomatology post whiplash and post concussion and the similarity of the rotational acceleration forces applied to the head in both injuries makes it reasonable to consider that the two conditions may arise from a common mechanism of injury, the presentations differing mainly in degree of severity. Indeed, it has been stated elsewhere that concussion can occur without a direct blow to the head if sufficient force is applied to the brain via a whiplash mechanism. ${ }^{6,52}$ Nevertheless, the two conditions are typically treated as separate entities. The SEP findings of our prospective study provide objective evidence that whiplash and concussion involve reversible pathophysiological changes affecting the same brain areas, providing support for the hypothesis that the overlapping clinical symptomatology post whiplash and concussion may reflect a similar underlying mechanism of rotational mild traumatic brain injury. However, it must be emphasized that our findings are preliminary, involving a small number of patients, and that we have not studied patients with milder, Grade 1 or 2 concussions, to confirm that these subjects would also lie along the same continuum, perhaps with a recovery trajectory midway between whiplash subjects and patients with Grade 3 concussions.

It is of interest to note that, in terms of self-reported clinical symptoms, subjects with whiplash injury actually tended to report a worsening of symptom severity with the passage of time, whereas the severity of self-reported symptoms diminished with time in the concussion patients. If indeed there is a common mechanism underlying both conditions, this may indicate that superimposed psychological factors, perhaps complicated by unresolved litigation and related disability claim issues, may play a greater contributory role to the persistence of chronic symptoms after whiplash injury ${ }^{2-4,53}$ than concussion. After whiplash and concussion injuries, clinical symptoms clearly outlasted the middle-latency SEP changes in many subjects, suggesting that N60 latency measurements will not be useful as a measure to assess chronic symptomatology. Future clinical usefulness of N60 latency measurements - providing the results of these studies can be replicated and extended - may be limited to diagnostic testing in the acute stage, and even here larger numbers of subjects will need to be evaluated to obtain an accurate estimate of test sensitivity. At the very least, however, 
the ability to record an objective physiological marker common to whiplash and concussion may form the basis for future investigations into the mechanisms underlying mild traumatic brain injury.

\section{ACKNOWLEDGEMENTS}

DZ was supported by Swiss National Science Foundation grant PA00A-101502.

\section{REFERENCES}

1. Ettlin TM, Kischka U, Reichmann S, Radii EW, Heim S, Wengen D, et al. Cerebral symptoms after whiplash injury of the neck: a prospective clinical and neuropsychological study of whiplash injury. J Neurol Neurosurg Psychiatry. 1992;55:943-8.

2. Radanov BP, Sturzenegger M, Di Stefano G, Schnidrig A. Relationship between early somatic, radiological, cognitive and psychosocial findings and outcome during a one-year follow-up in 117 patients suffering from common whiplash. $\mathrm{Br} \mathrm{J}$ Rheumatol. 1994;33:442-8.

3. Radonov BP, Sturzenegger M, Di Stefano G. Long-term outcome after whiplash injury. A 2-year follow-up considering features of injury mechanism and somatic, radiologic, and psychological findings. Medicine. 1995;74:281-97.

4. Schrader H, Obelieniene D, Bovim G, Surkiene D, Mickeviciene D, Miseviciene I, et al. Natural evolution of late whiplash syndrome outside the medicolegal context. Lancet. 1996;347:1207-11.

5. Leininger BE, Gramling SE, Farrell HD, Kreutzer JS, Peck EA. Neuropsychological deficits in symptomatic minor head injury patients after concussion and mild concussion. J Neurol Neurosurg Psychiatry. 1990;53:293-6.

6. Kelly JP, Rosenberg JH. Diagnosis and management of concussion in sports. Neurology. 1997;48:575-80.

7. Carroll LJ, Cassidy JD, Peloso PM, Borg J, von Holst H, Holm L, et al. Prognosis for mild traumatic brain injury: results of the WHO collaborating centre task force on mild traumatic brain injury. J Rehabil Med. 2004; 43 Suppl:S84-105.

8. Practice parameter: The management of concussion in sports (summary statement). Report of the Quality Standards Subcommittee. Neurology. 1997;48:581-5.

9. Riley L, Long D, Riley LH. The science of whiplash. Medicine. 1995; $74: 298-9$

10. Shaw NA. The neurophysiology of concussion. Prog Neurobiol. 2002;67:281-344.

11. Dupuis F, Johnston KM, Lavoie M, Lepore F, Lassonde M. Concussions in athletes produce brain dysfunction as revealed by event-related potentials. Neuroreport. 2000;11:4087-92.

12. Gaetz M, Goodman D, Weinberg H. Electrophysiological evidence for the cumulative effects of concussion. Brain Inj. 2000; $14: 1077-88$.

13. Allison T, McCarthy G, Wood CC, Williamson PD, Spencer DD. Human cortical potentials evoked by stimulation of the median nerve. II. Cytoarchitectonic areas generating long-latency activity. J Neurophysiol. 1989;62:711-22.

14. Goldring S, Aras E, Weber PC. Comparative study of sensory input to motor cortex in animals and man. Electroencephalogr Clin Neurophysiol. 1970;29:537-50.

15. Stöhr PE, Goldring S. Origin of somatosensory evoked scalp responses in man. J Neurosurg. 1969;31:117-27.

16. Denny-Brown D, Russell WR. Experimental cerebral concussion. Brain 1941;64:93-164.

17. Jane JA, Steward O, Gennarelli T. Axonal degeneration induced by experimental noninvasive minor head injury. J Neurosurg. 1985;62:96-100.

18. Ommaya AK, Faas F, Yarnell P. Whiplash injury and brain damage: an experimental study. JAMA. 1968;204:285-9.

19. Ommaya AK, Gennarelli TA. Cerebral concussion and traumatic unconsciousness. Correlation of experimental and clinical observations of blunt head injuries. Brain. 1974;97:633-54.
20. Shaw NA. Somatosensory evoked potentials after experimental head injury in the awake rat. J Neurol Sci. 1986;74:257-70.

21. Greenberg RP, Mayer DJ, Becker DP, Miller JD. Evaluation of brain function in severe human head trauma with multimodality evoked potentials. Part 1: evoked brain-injury potentials, methods, and analysis. J Neurosurg. 1977;47:150-62.

22. Greenberg RP, Becker DP, Miller JD, Mayer DJ. Evaluation of brain function in severe human head trauma with multimodality evoked potentials. Part 2: localization of brain dysfunction and correlation with posttraumatic neurological conditions. J Neurosurg. 1977;47:163-77.

23. Greenberg RP, Newlon PG, Hyatt MS, Narayan RK, Becker DP. Prognostic implications of early multimodality evoked potentials in severely head-injured patients. J Neurosurg. 1981;55:227-36.

24. Lindsay KW, Carlin J, Kennedy I, Fry J, McInnes A, Teasdale GM. Evoked potentials in severe head injury--analysis and relation to outcome. J Neurol Neurosurg Psychiatry. 1981;44:796-802.

25. Moulton RJ, Shedden PM, Tucker WS, Muller PJ. Somatosensory evoked potential monitoring following severe closed head injury. Clin Invest Med. 1994;17:187-95.

26. Pfurtscheller G, Schwarz G, Gravenstein N. Clinical relevance of long-latency SEPs and VEPs during coma and emergency from coma. Electroencephalogr Clin Neurophysiol. 1985;62:88-98.

27. He F, Liu X, Yang S, Zhang S, Xu G, Fang G, et al. Evaluation of brain function in acute carbon monoxide poisoning with multimodality evoked potentials. Environ Res. 1993;60:213-26.

28. Madl C, Grimm G, Kramer L, Yeganehfar W, Sterz F, Schneider B, et al. Early prediction of individual outcome after cardiopulmonary resuscitation. Lancet. 1993;341:855-8.

29. Madl C, Kramer L, Domanovits H, Woolard RH, Gervais H, Gendo A, et al. Improved outcome prediction in unconscious cardiac arrest survivors with sensory evoked potentials compared with clinical assessment. Crit Care Medicine. 2000;28:721-6.

30. Kramer L, Tribl B, Gendo A, Zauner C, Schneider B, Ferenci P, et al. Partial pressure of ammonia versus ammonia in hepatic encephalopathy. Hepatology. 2000;31:30-4.

31. Kullmann F, Hollerbach S, Holstege A, Scholmerich J. Subclinical hepatic encephalopathy: the diagnostic value of evoked potentials. J Hepatol. 1995;22:101-10.

32. Madl C, Grimm G, Ferenci P, Kramer L, Yeganehfar W, Oder W, et al. Serial recording of sensory evoked potentials: a noninvasive prognostic indicator in fulminant liver failure. Hepatology. 1994;20:1487-94.

33. Yang SS, Chu NS, Liaw YF. Somatosensory evoked potentials in hepatic encephalopathy. Gastroenterology. 1985;89:625-30.

34. Yang SS, Wu CH, Chiang TR, Chen DS. Somatosensory evoked potentials in subclinical portosystemic encephalopathy: a comparison with psychometric tests. Hepatology. 1998;27: 357-61.

35. Eisenhuber E, Madl C, Kramer L, Ratheiser K, Grimm G. Detection of subclinical brain dysfunction by sensory evoked potentials in patients with severe diabetic ketoacidosis. Intensive Care Med. $1997 ; 23: 587-9$

36. Grimm G, Madl C, Oder W, Druml W, Schneeweiss B, Laggner AN, et al. Evoked potentials in severe herpes simplex encephalitis. Intensive Care Med. 1991;17:94-7.

37. Hirsch SA, Hirsch PJ, Hiramoto H, Weiss A. Whiplash syndrome. Fact or fiction? Orthop Clin North Am. 1988;19:791-5.

38. Jacome DE. EEG in whiplash: a reappraisal. Clin Electroencephalogr. 1987;18:41-5.

39. Torres F, Shapiro SK. Electroencephalograms in whiplash injury. Arch Neurol. 1961;5:28-47.

40. Yarnell PR, Rossie GV. Minor whiplash head injury with major debilitation. Brain Inj. 1988;2:255-8.

41. Zumsteg D, Wieser HG. Effects of aging and sex on middle-latency somatosensory evoked potentials: normative data. Clin Neurophysiol. 2002;13:681-5.

42. Greenberg RP, Ducker TB. Evoked potentials in the clinical neurosciences. J Neurosurg. 1982;56:1-18.

43. Allison T, Goff WR, Abrahamian HA, Rosner BS. The effects of barbiturate anesthesia upon human somatosensory evoked responses. Electroencephalogr Clin Neurophysiol. 1963; Suppl 24:S68-75. 
44. Holbourn AHS. Mechanics of head injury. Lancet. 1943;2:438-41.

45. Gennarelli TA, Thibault LE, Adams JH, Graham DI, Thompson CJ, Marcincin RP. Diffuse axonal injury and traumatic coma in the primate. Ann Neurol. 1982;12:564-74.

46. Oppenheimer DR. Microscopic lesions in the brain following head injury. J Neurol Neurosurg Psychiatry. 1968;31:299-306.

47. Faden AI, Demediuk P, Panter SS, Vink R. The role of excitatory amino acids and NMDA receptors in traumatic brain injury. Science. 1989;244:798-800.

48. Katayama Y, Becker DP, Tamura T, Hovda DA. Massive increases in extracellular potassium and the indiscriminant release of glutamate following concussive brain injury. J Neurosurg. 1990;73:889-900.

49. Goff WR, Allison T, Shapiro A, Rosner BS. Cerebral somatosensory responses evoked during sleep in man. Electroencephalogr Clin Neurophysiol. 1966;21:1-9.
50. Kitamura Y, Kakigi R, Hoshiyama M, Koyama S, Nakamura A. Effects of sleep on somatosensory evoked responses in human: a magnetoencephalographic study. Brain Res Cogn Brain Res. 1996;4:275-9.

51. Grundy BL, Brown RH, Greenberg BA. Diazepam alters cortical evoked potentials. Anesthesiology. 1979;51:538.

52. Lindenberg R, Freytag E. Brainstem lesion characteristics of traumatic hyperextension of the head. Arch Pathol. 1970;90: 509-15.

53. Olsnes BT. Neurobehavioral findings in whiplash patients with longlasting symptoms. Acta Neurol Scand. 1989;80:584-8. 